\title{
Lifting Each Other Through Collaborations and Feedback
}

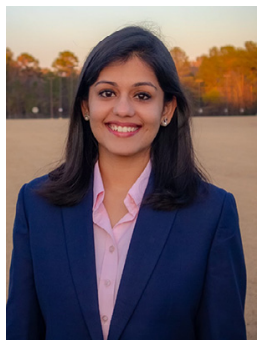

Gupta

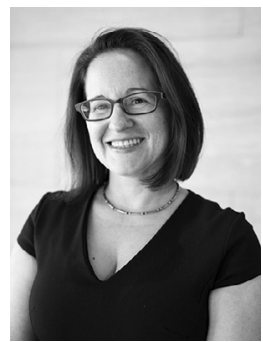

Viera

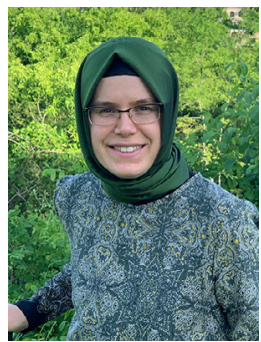

Baltaci

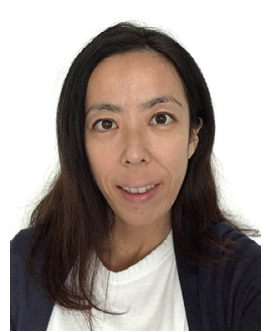

Sato
The Student Division of the Society for Nutrition Education and Behavior (SNEB) is a fairly young division that was established in 2019 and continues to provide an enriched experience for the student members. The 2020-21 school year was filled with compounded challenges of the pandemic. However, the student division witnessed an increased student membership and showed great enthusiasm in the 2020 and 2021 annual conferences of the SNEB. The student division leadership created a virtual higher education fair to connect students with graduate programs in 2020, organized a conference session in 2021, and relaunched the SNEB's mentorship program in 2021. Through this editorial, our primary objectives are to share the opportunities we plan to lead as SNEB student division and reflect on those key elements that can help current and future student division leaders successfully contribute to SNEB while still fulfilling our academic duties as students.

Planning is the crucial step for achieving goals. For this year, the student division has some exciting plans built on milestones achieved by the previous leadership. Our primary activities include planning a "for students and by students" conference session at the SNEB 2022 Annual Conference and organizing a webinar on developing application materials for academic and non-academic jobs for both students and early career professionals. This webinar will also address the common obstacles that students and early-career professionals face in the job market. Our third activity would be to increase the involvement of students in various fers. Additionally, we plan to increase SNEB membership and online presence (through social media platforms and virtual competitions) to increase knowledge and advancement in nutrition education and behavior while excelling as a team. These are the key elements to building a sustainable and efficient division that meets the society's mission and vision.

Teamwork and collaboration: Leading a division and getting involved in division leadership opportunities is a volunteer job. The only way for a division to sustain itself is increased participation by its members. Establishing a supportive environment is a crucial starting point to engage volunteers; thus, relationship building, and inclusivity need to be at the center of these efforts. This means eschewing transactional interactions with members and embracing each member for their unique talents and background. One way to approach teamwork and collaboration, especially when joining a new effort, is to be "curious, not furious." This axiom is attributed colloquially to Dr. Joy Browne, a renowned psychologist and syndicated talk radio show host. ${ }^{1}$

Humility: Humility is another leadership roles that the society ofcharacteristic that helps individuals in their approach to research and is a natural extension of a "curious not furious" mentality. ${ }^{2}$ The health benefits of taking a humble attitude are noted empirically. Mindfulness and self-awareness can help us strengthen our "humility muscles." 3

Communication: Communication is the key to achieving results while maintaining a work-life balance. Student division leadership highly recommends communicating your needs, capacities, and boundaries to people you work with. These may include immediate supervisors, work colleagues, and even professional division members.

Mentorship program: The SNEB mentorship program was well received, and 48 mentees/mentors are currently enrolled in the program. However, there was a small gap between their expectations: mentees expected longer program periods, whereas mentors suggested having an official meeting with mentees and having reserved mentors. We are conducting another survey and planning a meetup to improve the mentorship program.

Through the planned activities for this coming year, the student division leadership team offers a great deal to students who want to improve their professional and leadership skills and connect and collaborate with professions across the country. The division also provides their members a friendship that offers mutual support and might increase individuals' sense of belonging and professional purpose.

Kritika Gupta, MS

University of Mississippi, Oxford, MS

Stacey Viera, $\mathrm{MPH}$

The George Washington University, Arlington, VA

Aysegul Baltaci, MS

University of Minnesota Twin Cities, MN Sayaka Sato, MS

Ochanomizu University, Tokyo, Japan Opeyemi Adewumi, MSc

University of Alabama, Tuscaloosa, AL 
2 Gupta et al

\section{REFERENCES}

1. Baldoni J. Use humility to improve performance. Harvard Business Review. 2009. https://hbr.org/2009/11/use-humilityto-improve-perfor. Accessed November 16, 2021.

2. Nielsen R, Marrone JA. Humility: our current understanding of the construct and its role in organizations. Int J Manage Rev. 2018;20:805-824.
3. Davis DE, Hook JN. Measuring humility and its positive effects. APS Observer. 2013. https://www.psychologicalscience. org/observer/measuring-humility-and-itspositive-effects. Accessed November 16, 2021.

\section{ORCIDs}

Kritika Gupta: http://orcid.org/00000002-9609-312X
Stacey Viera: http://orcid.org/00000002-0834-0515 Aysegul Baltaci: http://orcid.org/ 0000-0001-6721-4327

Sayaka Sato: http://orcid.org/00000001-6721-0422

Opeyemi Adewumi: http://orcid.org/ 0000-0002-8763-9354 